\title{
Application of Pd-modified Nickel Foam Cathodes to the Process of Alkaline Water Electrolysis
}

\author{
Boguslaw Pierozynski*, Tomasz Mikolajczyk \\ Department of Chemistry, Faculty of Environmental Management and Agriculture, University of \\ Warmia and Mazury in Olsztyn, Plac Lodzki 4, 10-957 Olsztyn, Poland \\ *E-mail: bogpierozynski@yahoo.ca
}

doi: $10.20964 / 2016.06 .1$

Received: 21 February 2016 / Accepted: 17 March 2016 / Published: 1 May 2016

This work presents an investigation of hydrogen evolution reaction (HER) through the process of alkaline water electrolysis (AWE), performed by means of pure and palladium-modified nickel foam cathodes, and stainless steel anodes. Temperature-dependent kinetics of the HER were studied in 2 and $8 \mathrm{M} \mathrm{KOH}$, over the temperature range: $20-60{ }^{\circ} \mathrm{C}$ through a.c. impedance spectroscopy and d.c. galvanostatic electrochemical experiments. The charge-transfer resistance, exchange current-density for the HER and other electrochemical parameters for examined catalyst samples were presented.

Keywords: Renewable energy; Alkaline water electrolysis; Pd-modified Ni foam; HER; Impedance spectroscopy

\section{$\underline{\text { FULL TEXT }}$}

(C) 2016 The Authors. Published by ESG (www.electrochemsci.org). This article is an open access article distributed under the terms and conditions of the Creative Commons Attribution license (http://creativecommons.org/licenses/by/4.0/). 